\title{
Süreç Ortalaması için Tek Taraflı Medyan Kalite Kontrol Kartı
}

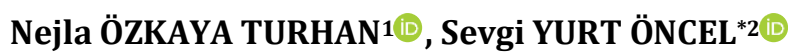 \\ ${ }^{1}$ Ankara Üniversitesi, Fen Fakültesi, İstatistik Bölümü, 06100, Ankara, Türkiye \\ ${ }^{2}$ Kırıkkale Üniversitesi, Fen-Edebiyat Fakültesi, İstatistik Bölümü, 71450, Kırıkkale, Türkiye
}

(Alınış / Received: 19.02.2020, Kabul / Accepted: 02.10.2020, Online Yayınlanma / Published Online: 20.12.2020)

\begin{abstract}
Anahtar Kelimeler
Ön istatistik,

Parametrik olmayan kalite

kontrol kartlarl,

Sira istatistikleri,

Tek-taraflı medyan kalite

kontrol kartları
\end{abstract}

\begin{abstract}
Özet: Bir fabrikanın üretim sürecinin kalitesini kontrol etmek amacıyla kullandığı en hızl, ve güvenilir yöntemlerden biri klasik Shewhart kontrol kartlarıdır. Ancak küçük örneklem durumunda, normal dağılım varsayımının şüpheli olduğu durumlarda ve çarpık ya da ağır kuyruklu dağılım söz konusu olduğunda Shewhart kontrol kartı ile süreci takip etmek riskli olacaktır. Böyle durumlarda parametrik olmayan kontrol kartları tercih edilir. Bu çalışmada tek taraflı parametrik olmayan kontrol kartları ayrıntılı olarak incelenmiştir. Ön istatistiğe dayalı tek taraflı medyan kontrol kartı için yanlış alarm oranı, çalışma uzunluğu ve ortalama çalışma uzunluğunun değerleri hesaplanmıștır. Medyan kontrol kartlarının tek dezavantajı hesaplamalarının güçlüğüdür. Bu güçlüğü gidermek için farklı örneklem hacimleri ve farklı olasılıklar için yapılan hesaplamalar orijinal tablolarda sunulmuştur. Ülkemizde üretim yapan ve istatistiksel kalite kontrol sürecine önem veren sanayi kuruluşları için hazırlanan bu tablolar büyük kolaylıklar sağlayacaktır. Çalışmanın sonunda bir veri seti üzerinde uygulama yapılarak ön istatistiğine dayalı medyan kontrol kartının kullanımı gösterilmiştir.
\end{abstract}

\section{One Sided Median Quality Control Chart for Process Mean}

\section{Keywords}

Precedence statistics, Nonparametric quality control charts,

Order statistics,

One-sided median quality control charts

\begin{abstract}
One of the fastest and most reliable methods used by a factory to control the quality of the production process is classical Shewhart control charts. However, in the case of a small sample size, in cases where the normal distribution assumption is suspect, in case of skewed or heavy-tailed distribution, it will be risky to follow the process with the Shewhart control charts. In such cases, nonparametric control cards are preferred. In this study, one-sided non-parametric control cards are examined in detail. Precedence statistics which is statistical independent of distribution were considered and the false alarm rate, working length and average working length values are calculated for this statistical oneway median control card. False alarm rate, a run length and average run length values calculated for the one-sided median control card based on precedence statistics. The only disadvantage of the median control cards is the difficulty of its calculations. To eliminate this difficulty, calculations were given for different sample sizes and different possibilities in the original tables. These tables, which were prepared for industrial organizations making production in our country and giving importance to the statistical quality control process, will provide great convenience. At the end of the study, an application of a median control card based on precedence statistics on a data set is shown.
\end{abstract}

\section{Giriş}

Süreç kontrolünde en çok kullanılan istatistiksel yöntemlerden biri kontrol kartları tekniğidir. İstatistiksel kalite kontrol kartları ilk kez Shewhart tarafından ortaya konulmuştur [1]. Birçok kontrol kartı arasında, Shewhart kontrol kartları sadeliği, uygulama kolaylığı ve süreçte ortaya çıkan büyük kaymaları saptama bakımından oldukça etkilidir. Shewhart kontrol kartlarını tanımlamak için, varsayalım ki sürecin konum parametresi $\theta$ ve $\theta^{\prime}$ nın yansız tahmin edicisi $T\left(X_{1}, X_{2}, \ldots, X_{n}\right)$ istatistiği olsun. $\left(E\left(T\left(X_{1}, X_{2}, \ldots, X_{n}\right)\right)=\theta\right.$ oluyorsa $T\left(X_{1}, X_{2}, \ldots, X_{n}\right)$ istatistiğine $\theta$ için yansız tahmin edici denir.) $T\left(X_{1}, X_{2}, \ldots, X_{n}\right)$ istatistiğinin standart sapması $\sigma_{T}$ olmak üzere Shewhart kontrol kartlarının limitleri 


$$
\text { ÜKL }=\theta+k \sigma_{T}, M L=\theta, A K L=\theta-k \sigma_{T}
$$

dır. Burada $k>0$ olmak üzere kontrol kartlarının orta çizgiden, standart sapmayla ifade edilen uzaklığını, ÜKL üst kontrol limitini, $A K L$ alt kontrol limitini ve $M L$ ise merkez çizgiyi göstermektedir [2, 3]. $\mathrm{Bu}$ kontrol limitleri $k$-sigma kontrol limitleri olarak ifade edilir. Genellikle $k=3$ alınır ve 3-sigma limitleri olarak bilinir. Shewhart kontrol kartlarında sürecin dağılımının normal dağılım olduğu ya da $T$ 'nin $\theta$ ortalamalı normal dağılıma yaklaştığı varsayımına dayanır. Örneğin, $\theta$ yerine süreç ortalaması $\mu$ alınabilir. Kalite kontrol kartlarının kullanılmasında ki asıl amaç, süreçteki değişikliği en kısa sürede tespit etmektir. Süreçte istenmeyen bir kayma olması durumunda, kontrol kartı mümkün olduğu kadar çabuk algilamalı ve kontrol dışı sinyal vermelidir. Doğru sinyalin algılanması ne kadar hızlı ise, kontrol kartı da o kadar verimlidir.

Yaygın olarak kullanılan Shewhart kontrol kartları, süreç çıktısının dağılımının normal dağılım olduğu varsayımına dayanmaktadır. Bu varsayım pratikte sağlanamayabilir. Süreç dağılımı ağır ya da hafif kuyruklu veya simetrik olmayan dağılımlar söz konusu olduğunda parametrik olmayan kontrol kartları emsalleri olan parametrik kontrol kartlarından daha iyi performans göstermektedir. Böyle durumlarda parametrik olmayan ya da dağılımdan bağımsız kontrol kartları tercih edilebilir. Parametrik olmayan kartların çoğu, sürekli bir dağılımın merkezini temsil eden konum parametresi üzerinedir. Konum parametresi olarak süreç dağılımının ortalaması ya da ortancası alınabilir. Parametrik olmayan kontrol kartların avantajı, ölçülen değişkenlerin dağılımları hakkında herhangi bir varsayım gerektirmemesi ve bu kartların aykırı değerler için sağlam (robust) özelliğe sahip olmasından dolayı çarpık ya da ağır kuyruklu dağılımlardan etkilenme olasılığının daha düșük olmasıdır. Ayrıca, sürecin kitle dağlımının varyansının bilinmesine veya tahmin edilmesine de gerek yoktur.

Dağılımdan bağımsız kontrol kartları üzerine birçok çalışma olsa da, bu konu hakkında ilk çalışmalar Bakir ve Reynolds tarafından yapılmıștır [4]. Daha sonraki yıllarda, Amin, Reynolds ve Bakir tarafından işaret test istatistiğine dayalı kontrol kartları ve Bakir tarafından işaretlenmiş rank istatistiğinden faydalanarak parametrik olmayan kontrol kartları oluşturulmuştur [5,6]. Janacek ve Meikle [7], Balakrishnan, Triantafyllou ve Koutras $[8,9]$, Chakraborti, Van der Laan ve Bakir [10], Chakraborti, Van der Laan ve Van de Wiel [11], Triantafyllou, $[12,13]$ 'nin parametrik olmayan kalite kontrol kartları hakkında önemli çalıșmaları bulunmaktadır. Shongwe, Malela-Majika ve Rapoo Shewhart kontrol kartları için w-of-w için çalışma uzunluğu kuralları geliştirmişlerdir [14]. Bu çalışmada ön istatistiklerden faydalanarak tek taraflı medyan kontrol kartları oluşturulmuştur. Eğer ön istatistiğine dayalı iki taraflı medyan kontrol kartlarına ihtiyaç duyulursa Turhan ve Öncel tarafından hazırlanmıș tablolar kullanılabilir [15].

Bir süreç, hedeflenen duruma göre çalışıyorsa, istatistiksel olarak süreç kontrol altında ya da kontrol içinde (in-control (IC)) olarak kabul edilir. Sürecin kontrol altında olmadığı zaman, kontrol dışı olduğu (out-of-control (OOC)) söylenir. Böyle durumda, bazı özel sebeplerin süreci etkilediği düşünülür ve bu sebepler belirlenerek, ortadan kaldırılır. Süreç tekrar IC durumuna geri getirilir.

Dağılımdan bağımsız bir kontrol kartı sağlam istatistiklere dayanan grafiksel bir araçtır ve süreç değişkenliğini anlamak, kaliteyi korumak ve geliştirmek için objektif bir yol sağlar. Bu nedenle, kontrol kartı grafiği istatistik süreç kontrolünde önemli bir rol oynar. Kontrol kartları alt kontrol limiti, üst kontrol limiti ve merkez çizgi olmak üzere üç yatay çizgiden oluşur. Bu üç çizgi yardımıyla sürecin IC ya da OOC olduğuna karar verilir. Süreç kontrol altındayken alınan $X_{1}, X_{2} \ldots, X_{m}$ referans örneklemi kullanılarak kontrol limitlerinin sınırları belirlenir. Sürecin kontrol altında olup olmadığını test etmek için sistemden $Y_{1}, Y_{2}, \ldots, Y_{n}$ test örneklemi alınır. Süreç için belirlenen istatistiğe göre (örneğin ortalama) sistemin kontrol altında olup olmadığı belirlenmeye çalışılır. Belirlenen istatistik değerleri kontrol limitlerinin üzerine ya da dışına düşerse sistemin kontrol dişında olduğu belirtilir. Bu olaya sinyal ya da alarm denir. Bir sinyal gözlendiğinde, genellikle sinyalin kaynağını bulmak için bir araștırma bașlatılır ve gerekiyorsa sisteme müdahale edilir. Sistem gerçekte IC iken sistemin OOC olduğu belirtilirse yanlış alarm verilmiş olur.

Kontrol kartları ile hipotez testleri ve güven aralıkları arasında benzerlikler vardır. Shewhart kontrol kartları kullanıldığında kart istatistiği kontrol limitleri arasına düştüğünde sürecin kontrol altında olduğu, kart istatistiği kontrol limitlerinin üstüne veya altına düștüğünde ise sürecin kontrol dıșında olduğu belirtilir. Hipotez testlerinde olduğu gibi, kart istatistiğinin değeri ve karar bölgesine göre karar verilir. Kart istatistiği $T$ olmak üzere, standart sapması $\sigma_{T}$ ve süreç ortalaması $\theta$ için hipotez $H_{0}: \theta=$ $\theta_{0}, H_{1}: \theta \neq \theta_{0}$ şeklinde kurulur. $T$ istatistiği olarak örneklem ortalaması ve süreç ortalaması da $\mu$ olmak üzere $\mu$ 'nün belirlenmiş bir $\mu_{0}$ değerine eşit olup olmaması hipotezi $H_{0}: \mu=\mu_{0}, H_{1}: \mu \neq \mu_{0}$ şeklinde kurulur [2].

Bir kontrol kartının performansını incelerken hipotez testlerinde olduğu gibi hatalar ve hataların olasıllkları hesaplanabilir. I tip hata, aslında sistem IC olduğunda sistemin OOC olarak bildirildiği olaydır. II. tip hata ise gerçekte sistemin OOC durumunda olduğu fakat sistemin IC olarak bildirildiği olaydır. Yani, 
$\alpha=P($ I.tip hata $)$

$=P($ sistemin OOC gözükmesi $\mid$ sistem gerçekte IC $)$

$$
\begin{aligned}
& \beta=P(\text { II.tip hata }) \\
& =P(\text { sistemin IC gözükmesi|sistem gerçekte OOC })
\end{aligned}
$$

I. tip hata, genellikle yanlış alarm $(F A)$ ve bu olayın gerçekleşme olasılı̆̆ı da yanlış alarm oranı (false alarm rate- $F A R$ ) olarak ifade edilir.

Genel olarak istatistiksel süreç kontrolünün pratikte iki așamada uygulandığı kabul edilir: Faz I (geriye dönük faz ) ve Faz II (ileriye dönük faz). Faz I aşaması öncelikle süreci daha iyi anlamak ve süreç istikrarını değerlendirmekten oluşur. Genellikle geçmiş verileri veya başlangıçtaki verileri analiz ederek, değişim nedenlerini saptayarak ve ortadan kaldırarak süreci kontrol altına almaya çalışmaktan oluşur. Faz I analizi, tipik olarak tasarım, tahmin (bilinmeyen parametrelerin tahmini) ve kontrol limitlerinin oluşturulması ile ilgili hususları içerir. $\mathrm{Bu}$ fazda kontrol limitleri genellikle deneme limitleri olarak görülür. Bilinmeyen bir parametre varsa, kontrol kartlarının oluşturulmasında kullanılan kontrol içi verilerden (referans veri olarak da bilinen) tahmin edilir. Faz II'de ise, Faz I'de yapılan parametre tahminleri ve hesaplanan kontrol limitleri kullanarak süreç izlenir.

\section{2. Ön (Precedence) İstatistik}

$X_{1}, X_{2}, \ldots, X_{m} \quad$ örneklem $\quad F(x)$ dağılımından $Y_{1}, Y_{2}, \ldots, Y_{n}$ örneklemi $G(x)$ dağılımından alınmış $m$ ve $n$ boyutlu iki bağımsız örneklem olmak üzere $X_{1: m} \leq X_{2: m} \leq \ldots \leq X_{m: m} \quad$ ve $\quad Y_{1: n} \leq Y_{2: n} \leq \ldots \leq Y_{n: n}$ rasgele değișkenleri sırası ile bu örneklemlerin sıra istatistikleri olsun. $X$ örnekleminden $X_{j: m}$ sira istatistiği seçilsin. Belirlenen $X_{j: m}$ sıra istatistiğinin altında kalan toplam $Y$ gözlemlerin sayısı $W_{j}$ ile gösterilsin. $\mathrm{Bu}$ şekilde belirlenen $X_{j: m}$ sıra istatistiği bir rasgele bariyer noktası ve $W_{j}$ istatistiğine de ön (precedence) istatistik denir. Bu istatistikler yaşam analizinde, güvenilirlikte, sel ve kuraklık gibi birçok doğa olaylarının modellenmesinde, kalite kontrolünde ve iki örneklemin aynı dağılımdan gelip gelmediğini yani $H_{0}: F(t)=G(t)$ hipotezini test etmek için de kullanılır. $W_{j}$ ön istatistiklerine dayanan testler ön test olarak adlandırılır. Ön test istatistikleri dağılımdan bağımsız istatistiklerdir.

Ön istatistiği $P\left(Y_{j: n}>X_{i: m}\right)$ şeklinde gösterelim. $Y$ gözlemlerinden $X_{i: m}$ bariyerinin altında $j-1$ tane gözlem olacaktır. Yani $P\left(W_{j} \leq j-1\right)$ olasılığı $H_{0}$ hipotezinin doğruluğu koşulunda yani $F=G$ olması durumun da $w=0,1, \ldots, m$ için

$$
P\left(W_{j}=w\right)=\frac{\left(\begin{array}{c}
j+w-1 \\
w
\end{array}\right)\left(\begin{array}{c}
m+n-j-w \\
m-w
\end{array}\right)}{\left(\begin{array}{c}
m+n \\
n
\end{array}\right)}
$$

olarak elde edilir. Kalite kontrol, güvenilirlik gibi alanlarda çoğunlukla olasılık dağılımları bilinmez ya da normal dağılım olmadığı durumlarla sıklıkla karşılașılır. Böyle durumlarda dağılımdan bağımsız istatistikler olan ön istatistikler rahatlıla kullanılabilir. Tablo 1'de $m=9, n=11, j=1,6,11$ değerlerine göre $W_{j}^{\prime}$ nin dağılımı elde edilmiştir.

Aşağıda verilen Tablo 1 ve Şekil 1-3'e göre $H_{0}: F(t)=$ $G(t)$ hipotezinin doğru olduğu varsayımı altında (süreç kontrol altındayken) $W_{j}$ istatistiğinin dağılımı, dağılımdan bağımsızdır.

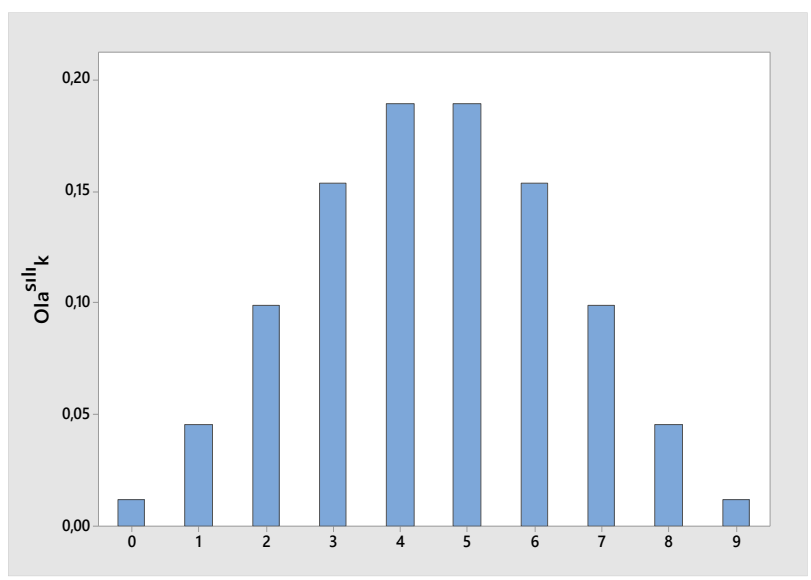

Şekil 1. $j=6$ için $W_{j}$ 'nin dağılımı simetriktir

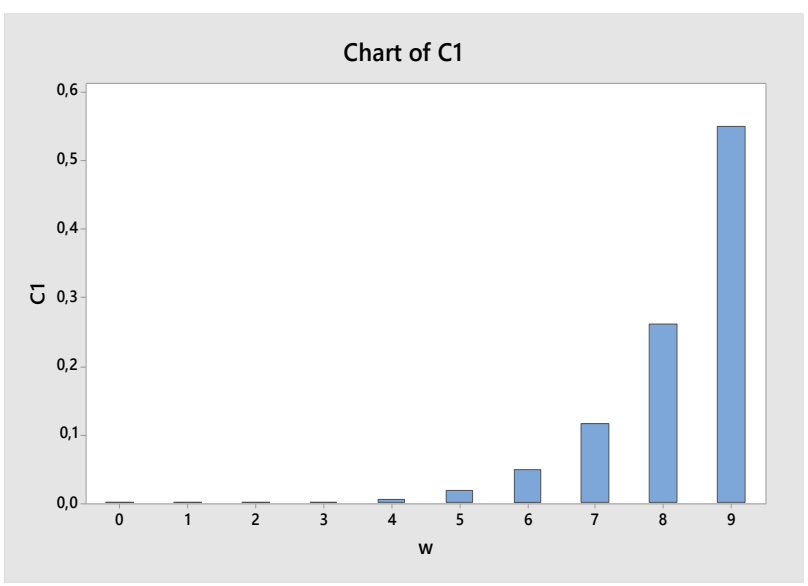

Şekil 2. $j=11$ için $W_{j}^{\prime}$ nin dağılımı sola çarpıktır.

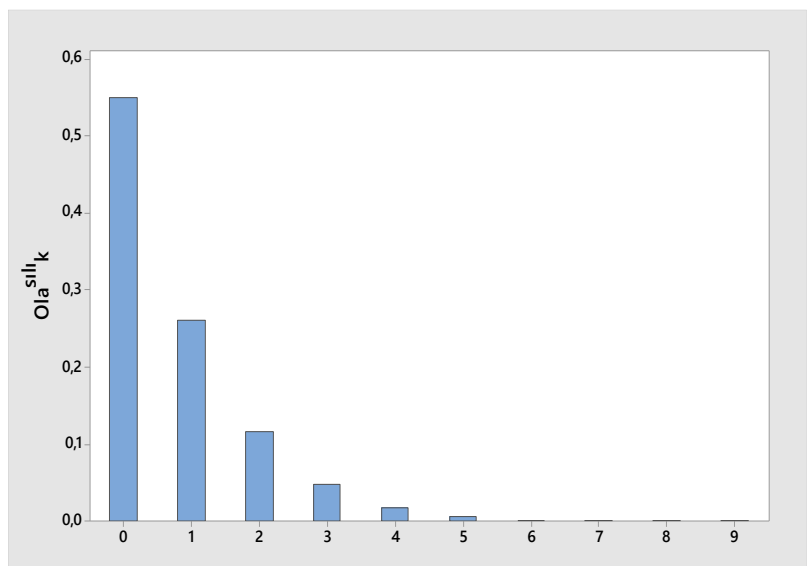

Şekil 3. $j=1$ için $W_{j}$ 'nin dağılımı sağa çarpıktır. 
Tablo 1: $n=11, m=9$ olması durumunda $W_{j}$ istatistiği için ön (precedence) istatistiğinin olasılık dağılımı

\begin{tabular}{|c|c|c|c|c|c|c|c|c|c|c|c|}
\hline & $\mathrm{w}$ & $\mathbf{0}$ & 1 & 2 & 3 & 4 & 5 & 6 & 7 & 8 & 9 \\
\hline \multirow[b]{2}{*}{$j=6$} & $P\left(W_{j}=w\right)$ & 0.0119 & 0.0460 & 0.099 & 0.154 & 0.189 & 0.189 & 0.154 & 0.099 & 0.0460 & 0.0119 \\
\hline & $F_{W}(w)$ & 0,0119 & 0,0579 & 0,1569 & 0,311 & 0,500 & 0,689 & 0,8431 & 0,9421 & 0,9881 & 1,000 \\
\hline \multirow[b]{2}{*}{$j=11$} & $P\left(W_{j}=w\right)$ & 0.00033 & 0.0024 & 0.0096 & 0.0275 & 0.0619 & 0.1149 & 0.1788 & 0.2299 & 0.2299 & 0.1447 \\
\hline & $F_{W}(w)$ & 0,00033 & 0,0027 & 0,0124 & 0,0399 & 0,1018 & 0,2167 & 0,3955 & 0,6254 & 0,8553 & 1,000 \\
\hline \multirow{2}{*}{$j=1$} & $P\left(W_{j}=w\right)$ & 0,550 & 0,2605 & 0,1158 & 0,0477 & 0,0179 & 0,0060 & 0,0017 & 0,00039 & 0,00006 & 0.000005 \\
\hline & $F_{W}(w)$ & 0,550 & 0,8105 & 0,9263 & 0,9740 & 0,9919 & 0,9978 & 0,9995 & 0,9999 & 0,99999 & 1,0000 \\
\hline
\end{tabular}

\section{Tek Taraflı Ön Kontrol Kartları}

Süreç ortalamasında ki değişikliği (artış ya da azalışı) belirlemek için tek taraflı veya iki taraflı kontrol kartları tasarlanır. Süreçte meydana gelen belirli bir yöndeki değişimle, yani artış veya azalışla ilgilenildiğinde tek taraflı kontrol kartlarından faydalanılır. Yukarı taraflı (veya așağı) değișiklikleri tespit etmek için tek taraflı üst (veya alt) kontrol kartları kullanılırken, süreçte yukarı veya aşağı olan bazı değişiklikleri belirlemek için de iki taraflı kontrol kartları kullanılır.

Tek taraflı kontrol kartları, özellikle bir süreç parametresindeki sadece yukarı (ya da sadece așağı) doğru bir kaymanın söz konusu olduğu durumlarda kullanışlıdır. Örneğin, paraşüt yapmak için kullanılan malzemenin kopma mukavemetini takip ediyor olabiliriz. Malzemenin kopma mukavemeti azalırsa kritik bir zamanda yırtılabilir, oysa malzemenin kopma mukavemeti artarsa, malzeme kullanım sırasında yırtılmayacağından, kullanıcı için yararlıdır. Böyle bir durumda, tek taraflı alt kontrol kartı kullanmak yeterli olacaktır. Çünkü sadece süreç parametresinde ki aşağı doğru bir kaymayı tespit etmekle ilgilenilir [3].

Örneğin, ilgilenilen süreç parametresinin yukarı doğru kayması ile ilgileniliyorsa Ü $K L=X_{b: m}$ değeri kullanılabilir. Burada yer alan değeri önceden belirlenen $P_{0}$ olasılık değerine ve (1) eşitliğinde verilen $W_{j}$ 'nin dağılımı kullanılarak

$$
P\left(Y_{j: n} \geq X_{b: m}\right)=P\left(b \leq W_{j} \leq m\right) \leq\left(1-P_{0}\right)
$$

eşitsizliğinden elde edilir. Eğer düşük değerlerin tespiti ile ilgileniliyorsa tek yanlı ön kontrol kartı için $A K L=X_{a: m}$ kullanılır.

\section{1. Çalışma uzunluğu dağılımı}

Bir kontrol kartının performansı genellikle çalıșma uzunluğu (run length) dağılımı ile değerlendirilir. Çalışma uzunluğu, ilk kontrol dışı sinyalden önce yer alan alt grupların sayısını gösteren kesikli bir rastgele değişkendir. Çalışma uzunluğu $N$ ile gösterilir. Genellikle bir kontrol grafiğinin performansını değerlendirmek için çalışma uzunluğunun dağılımından faydalanılır. Bunlardan en önemlisi çalışma uzunluğu dağılımı kullanılarak hesaplanan, çalışma uzunluğu dağılımının beklenen değeridir (Average Run Length-ARL).

\subsection{Ortalama çalışma uzunluğu}

Bir kontrol kartının en önemli performans ölçüsü ortalama çalışma uzunluğudur. Kontrol kartının $A R L$ 'si, bir kontrol kartı ilk kez kontrol dıșı sinyal verene kadar ki alt grupların beklenen sayısıdır. Eğer süreç kontrol altında ise ilk kontrol kartı sinyalinden önce alınan alt grupların beklenen sayısı, kontrol içi ortalama çalışma uzunluğu olarak adlandırılır ve $A R L_{0}$ olarak gösterilir. Eğer süreç kontrol dışında ise ise ilk kontrol kartı sinyalinden önce alınan alt grupların beklenen sayısı kontrol dişı ortalama çalışma uzunluğu denir ve $A R L_{1}$ ile gösterilir. Süreç kontrol altında iken ortalama çalışma uzunluğunun büyük, süreç kontrol dişındayken ortalama çalışma uzunluğunun küçük olması istenir.

\subsection{Alt kontrol limitleri}

Tek taraflı alt kontrol limiti $A K L=X_{a: m}, 1 \leq a \leq m$ olarak alınırsa sürecin sinyal vermemesi olayı $Y_{j: n} \geq$ $X_{a: m}$ 'dir. Buradaki $a$ değeri önceden belirlenmiş 1 $P_{0}$ yanlış alarm oranına bağlı olarak

$P\left(Y_{j: n} \leq X_{a: m}\right)=P\left(0 \leq W_{j} \leq a-1\right) \leq\left(1-P_{0}\right)$

eşitsizliğinden elde edilir [10-11]. $Y_{j: n} \geq X_{a: m}$ olayının olasılığı yani sürecin sinyal vermemesi olasıllğ̆

$$
\begin{aligned}
p_{A} & =P\left(Y_{j: n} \geq X_{a: m}\right)=E_{X_{a: m}} P\left(Y_{j: n} \geq X_{a: m} \mid X_{a: m}\right) \\
& =E_{X_{a: m}} P\left(G\left(Y_{j: n}\right) \geq G\left(X_{a: m}\right) \mid X_{a: m}\right) \\
& =E_{U_{a: m}} P\left(U_{j: n} \geq G F^{-1}\left(U_{a: m}\right) \mid U_{a: m}\right) \\
& =\int_{0}^{1} P\left(U_{j: n} \geq G F^{-1}(t) \mid U_{a: m}=t\right) f(t) d t \\
& =\int_{0}^{1}\left(\int_{G F^{-1}(t)}^{1} \frac{1}{B(j, n-j+1)} u^{j-1}(1-u)^{n-j} d u\right) f(t) d t
\end{aligned}
$$

$f(t), U_{a: m}$ sira istatistiğinin olasılık yoğunluk fonksiyonu olmak üzere

$$
\begin{aligned}
& p_{A}=\int_{0}^{1}\left[\frac{1}{B(j, n-j+1)} \sum_{h=0}^{n-j} \frac{(-1)^{h}}{j+h}\left(\begin{array}{c}
n-j \\
h
\end{array}\right)\right. \\
& \left.\left(1-G F^{-1}(t)\right)^{(j+h)}\right] \frac{m !}{(a-1) !(m-a) !} t^{a-1}(1-t)^{m-a} d t
\end{aligned}
$$

elde edilir. Burada $B(j, n-j+1)=\frac{(j-1) !(n-j) !}{n !}$ dir.

$H_{0}: F(x)=G(x)$ hipotezinin doğruluğu altında

$G F^{-1}(t)=F F^{-1}(t)=t$ olacağından $p_{A}$ olasılı̆̆ 


$$
\begin{aligned}
p_{A}= & \int_{0}^{1}\left[\frac{1}{B(j, n-j+1)} \sum_{h=0}^{n-j} \frac{(-1)^{h}}{j+h}\left(\begin{array}{c}
n-j \\
h
\end{array}\right)\right. \\
& \left.\times(1-t)^{(j+h)}\right] \times \frac{m ! t^{a-1}(1-t)^{m-a}}{(a-1) !(m-a) !} d t
\end{aligned}
$$

olacaktır. Bu durumda yanlış alarm oranı

$$
\begin{aligned}
F A R= & 1-\int_{0}^{1}\left[\frac{1}{B(j, n-j+1)} \sum_{h=0}^{n-j} \frac{(-1)^{h}}{j+h}\left(\begin{array}{c}
n-j \\
h
\end{array}\right)\right. \\
& \left.\times(1-t)^{(j+h)}\right] \times \frac{m ! t^{a-1}(1-t)^{m-a}}{(a-1) !(m-a) !} d t
\end{aligned}
$$

eşitliğinden hesaplanır.

Çalışma uzunluğu rastgele değişkeni olan $N$ 'in dağılımı, $p_{A}=P\left(Y_{j: n} \geq X_{a: m}\right)$ olasilığ ile geometrik dağllımına sahiptir. $N$ rastgele değişkeninin dağılımı

$P(N=k)=E_{X_{a: m}}\left(\left(p_{A}(x)\right)^{k-1}-\left(p_{A}(x)\right)^{k}\right)$,

$k=1,2, \ldots$ olmak üzere

$E_{X_{a: m}}\left(p_{A}(x)^{k}\right)=E_{U_{a: m}}\left[P\left(U_{(j: n)} \geq G F^{-1}\left(U_{(a: m)}\right)\right)\right]^{k}$

$=\int_{0}^{1}\left[P\left(U_{(j: n)} \geq G F^{-1}(t)\right)\right]^{k} f(t) d t$

$=\int_{0}^{1}\left[\int_{G F^{-1}(t)}^{1} \frac{1}{B(j, n-j+1)} u^{j-1}(1-u)^{n-j} d u\right]^{k} f(t) d t$

$=\int_{0}^{1}\left[\int_{G F^{-1}(t)}^{1} \frac{1}{B(j, n-j+1)} u^{j-1}(1-u)^{n-j} d u\right]^{k}$

$\times \frac{m !}{(a-1) !(m-a) !} t^{a-1}(1-t)^{m-a} d t$

$=\int_{0}^{1}\left[\frac{1}{B(j, n-j+1)} \sum_{h=0}^{n-j} \frac{(-1)^{h}}{j+h}\left(\begin{array}{c}n-j \\ h\end{array}\right) \times\right.$

$$
\left.\left(1-G F^{-1}(t)^{(j+h)}\right)\right]^{k} \frac{m ! t^{a-1}(1-t)^{m-a}}{(a-1) !(m-a) !} d t
$$

$$
=D_{A}^{*}(k)
$$

ve

$P(N=k)=D_{A}^{*}(k-1)-D_{A}^{*}(k)$,

$k=1,2,3, \ldots$ ve $D_{A}^{*}(0)=1$

dır. Süreç kontrol altındayken çalışma uzunluğunun dağılımı

$P(N=k)=D_{A}(k-1)-D_{A}(k)$,

$k=1,2,3, \ldots$ ve $D_{A}(0)=1$ olmak üzere (6) eşitliğinde $F=G$ ve $G F^{-1}(t)=$ $F F^{-1}(t)=t$ olacağından

$D_{A}(k)=\int_{0}^{1}\left[\frac{1}{B(j, n-j+1)} \sum_{h=0}^{n-j} \frac{(-1)^{h}}{j+h}\left(\begin{array}{c}n-j \\ h\end{array}\right)\right.$

$\left.(1-t)^{(j+h)}\right]^{k} \frac{m !}{(a-1) !(m-a) !} t^{a-1}(1-t)^{m-a} d t$

olarak elde edilir. Ortalama çalışma uzunluğu ise

$A R L=\sum_{k=0}^{\infty} E_{X_{(a: m)}}\left(p_{A}(x)^{k}\right)=\sum_{k=0}^{\infty} D_{A}^{*}(k)$

dır. (6) eşitliği kullanılarak

$$
\begin{aligned}
A R L= & \sum_{k=0}^{\infty} \int_{0}^{1}\left[\frac{1}{B(j, n-j+1)} \sum_{h=0}^{n-j} \frac{(-1)^{h}}{j+h}\left(\begin{array}{c}
n-j \\
h
\end{array}\right)\right. \\
\left.\left(1-G F^{-1}(t)^{(j+h)}\right)\right]^{k} & \frac{m ! t^{a-1}(1-t)^{m-a}}{(a-1) !(m-a) !} d t \\
C_{A}(t, j, n, F, G)= & \frac{1}{B(j, n-j+1)} \sum_{h=0}^{n-j} \frac{(-1)^{h}}{j+h}\left(\begin{array}{c}
n-j \\
h
\end{array}\right) \\
& \times\left[1-G F^{-1}(t)\right]^{(j+h)}
\end{aligned}
$$

olmak üzere

$$
\begin{aligned}
A R L= & \int_{0}^{1} \sum_{k=0}^{\infty}\left(C_{A}(t, j, n, F, G)\right)^{k} \\
& \times \frac{m !}{(a-1) !(m-a) !} t^{a-1}(1-t)^{m-a} d t \\
A R L= & \int_{0}^{1}\left[1-C_{A}(t, j, n, F, G)\right]^{-1} \\
& \times \frac{m !}{(a-1) !(m-a) !} t^{a-1}(1-t)^{m-a} d t
\end{aligned}
$$

elde edilir. Süreç kontrol altındayken yani $H_{0}: F=G$ olması durumunda (10) eşitliğinden

$$
\begin{aligned}
A R L_{0}= & \sum_{k=0}^{\infty} D(k)=\int_{0}^{1}\left[1-C_{A}(t, j, n)\right]^{-1} \\
& \times \frac{m !}{(a-1) !(m-a) !} t^{a-1}(1-t)^{m-a} d t
\end{aligned}
$$

olarak bulunur. Burada

$C_{A}(t, j, n)=\frac{1}{B(j, n-j+1)} \sum_{h=0}^{n-j} \frac{(-1)^{h}}{j+h}\left(\begin{array}{c}n-j \\ h\end{array}\right)(1-t)^{(j+h)}$,

dir.

$A R L_{0}{ }^{\prime}$ in sonlu olması için $m, n, a$ ve $j$ sabitleri üzerinde belirli koșullar vardır. Chakraborti, S., Van 
der Laan, P., Van de Wiel, M. A.'in çalışmasında $A R L_{0}$ 'ın sonlu olması için gerek ve yeter koşulun $(m-b)-(n-j)>0$ olduğu ispatlanmıştır [11].

Aşağıdaki tablolar ön istatistiği kullanılarak oluşturulan medyan kontrol kartları için sırasıyla $m=50,100,250,500,750,1000 ; n=5,11,15,25,31$; $P_{0}=0.95,0.99,0.9973$ değerleri için $a$ ( 2 eşitliğinden), yanlış alarm oranı (FAR) (5 eşitliğinden) ve ortalama çalışma uzunluğu $\left(A R L_{0}\right) \quad(12$ eşitliğinden $)$ hesaplanmıştır.

\section{4. Üst Kontrol Limiti}

Tek taraflı kontrol limitlerin alt kontrol limiti Ü $K L=$ $X_{b: m}, 1 \leq b \leq m$ olarak alınırsa sürecin sinyal vermemesi olayı $Y_{j: n} \leq X_{b: m}$ 'dir. Burada $b$ değeri önceden belirlenmiş $1-P_{0}$ yanlış alarm oranına bağlı olarak

$$
P\left(Y_{j: n} \geq X_{b: m}\right)=P\left(b \leq W_{j} \leq m\right) \leq\left(1-P_{0}\right)
$$

Tablo 2. Süreç kontrol altındayken medyan kontrol kartı için seçilen keyfi $m, n$ ve $P_{0}=0.95$ değerlerine göre belirlenen $A K L=X_{a}$ değerleri için hesaplanan $F A R$ ve $A R L_{0}$ değerlerinin tablosu

\begin{tabular}{|c|c|c|c|c|c|c|c|c|c|}
\hline \multirow[b]{2}{*}{$P_{0}$} & \multirow[b]{2}{*}{$n$} & \multirow[b]{2}{*}{$j$} & \multicolumn{7}{|c|}{ Referans örneklem hacmi - m } \\
\hline & & & & 50 & 100 & 250 & 500 & 750 & 1000 \\
\hline \multirow{3}{*}{0.95} & \multirow{3}{*}{5} & \multirow{3}{*}{3} & (a) & $(10)$ & (19) & $(47)$ & (95) & $(142)$ & $(189)$ \\
\hline & & & FAR & 0.0492 & 0.0466 & 0,0476 & 0,0497 & 0,0495 & 0,0494 \\
\hline & & & ARL & 29.54 & 25.77 & 22.55 & 20.8 & 20.65 & 20.58 \\
\hline \multirow{3}{*}{0.95} & \multirow{3}{*}{11} & \multirow{3}{*}{6} & (a) & (13) & (27) & (68) & $(135)$ & (203) & $(271)$ \\
\hline & & & FAR & 0.039 & 0.0477 & 0.05 & 0.049 & 0.0493 & 0.0496 \\
\hline & & & ARL & 79.09 & 32.59 & 23.42 & 22.22 & 21.35 & 20.93 \\
\hline \multirow{3}{*}{0.95} & \multirow{3}{*}{15} & \multirow{3}{*}{8} & (a) & (15) & (30) & (75) & (149) & $(224)$ & (299) \\
\hline & & & FAR & 0.0497 & 0.05 & 0.05 & 0.048 & 0,0489 & 0.0492 \\
\hline & & & ARL & 91.05 & 36.85 & 24.93 & 23.13 & 22.01 & 21.89 \\
\hline \multirow{3}{*}{0.95} & \multirow{3}{*}{21} & \multirow{3}{*}{11} & (a) & (16) & (31) & (81) & (163) & $(245)$ & (327) \\
\hline & & & FAR & 0.047 & 0.045 & 0.0473 & 0.0486 & 0.049 & 0.0492 \\
\hline & & & ARL & 306.54 & 59.34 & 54.85 & 24.17 & 22.66 & 21.96 \\
\hline \multirow{3}{*}{0.95} & \multirow{3}{*}{25} & \multirow{3}{*}{13} & (a) & (16) & (33) & (85) & $(170)$ & (255) & $(340)$ \\
\hline & & & FAR & 0.038 & 0.0433 & 0.05 & 0.0497 & 0.0493 & 0.049 \\
\hline & & & ARL & 1621.55 & 82.29 & 29.40 & 24.42 & 23.05 & 22.4 \\
\hline \multirow{3}{*}{0.95} & \multirow{3}{*}{31} & \multirow{3}{*}{16} & $(a)$ & (17) & (35) & (88) & (177) & $(266)$ & (355) \\
\hline & & & FAR & 0.044 & 0.0497 & 0.0481 & 0.0487 & 0.0489 & 0.0491 \\
\hline & & & ARL & 597.34 & 98.62 & 35.15 & 26.24 & 23.99 & 22.98 \\
\hline
\end{tabular}

Tablo 3 -Süreç kontrol altındayken medyan kontrol kartı için seçilen keyfi $m, n$ ve $P_{0}=0.99$ değerlerine göre belirlenen $A K L=X_{a}$ değerleri için hesaplanan $F A R$ ve $A R L_{0}$ değerlerinin tablosu

\begin{tabular}{|c|c|c|c|c|c|c|c|c|c|}
\hline \multirow[b]{2}{*}{$P_{0}$} & \multirow[b]{2}{*}{$n$} & \multirow[b]{2}{*}{$j$} & \multicolumn{7}{|c|}{ Referans örneklem hacmi - m } \\
\hline & & & & 50 & 100 & 250 & 500 & 750 & 1000 \\
\hline \multirow{3}{*}{0.99} & \multirow{3}{*}{5} & \multirow{3}{*}{3} & (a) & (5) & (11) & $(27)$ & (53) & (79) & $(105)$ \\
\hline & & & FAR & 0.0007 & 0.01 & 0,01 & 0,0099 & 0,0098 & 0,0097 \\
\hline & & & ARL & 522.86 & 153.07 & 115.09 & 109.58 & 107.84 & 107 \\
\hline \multirow{3}{*}{0.99} & \multirow{3}{*}{11} & \multirow{3}{*}{6} & (a) & (9) & (19) & (49) & (96) & $(145)$ & (192) \\
\hline & & & FAR & 0.0079 & 0.0097 & 0.01 & 0.0097 & 0.01 & 0.0098 \\
\hline & & & ARL & 1676.3 & 262.9 & 127.45 & 121.99 & 111.94 & 110.22 \\
\hline \multirow{3}{*}{0.99} & \multirow{3}{*}{15} & \multirow{3}{*}{8} & (a) & (11) & (22) & (57) & (113) & $(170)$ & (228) \\
\hline & & & FAR & 0.01 & 0.0093 & 0.01 & 0.0096 & 0,0097 & 0.01 \\
\hline & & & ARL & 2935.23 & 401.91 & 148.48 & 129.49 & 119.33 & 111.46 \\
\hline \multirow{3}{*}{0.99} & \multirow{3}{*}{21} & \multirow{3}{*}{11} & (a) & (12) & (25) & (65) & (131) & (197) & (263) \\
\hline & & & FAR & 0.0082 & 0.0088 & 0.01 & 0.0099 & 0.01 & 0.01 \\
\hline & & & ARL & 25069.5 & 816.51 & 188.78 & 135.54 & 122.31 & 116.34 \\
\hline \multirow{3}{*}{0.99} & \multirow{3}{*}{25} & \multirow{3}{*}{13} & (a) & (13) & (27) & (69) & (139) & (209) & $(280)$ \\
\hline & & & FAR & 0.0097 & 0.01 & 0.0099 & 0.0098 & 0.0097 & 0.01 \\
\hline & & & ARL & $\infty$ & 1019.31 & 216.66 & 147.21 & 130.76 & 119.44 \\
\hline \multirow{3}{*}{0.99} & \multirow{3}{*}{31} & \multirow{3}{*}{16} & $(a)$ & (14) & (29) & (74) & (149) & (224) & (299) \\
\hline & & & FAR & 0.01 & 0.01 & 0.01 & 0.01 & 0.0098 & 0.0098 \\
\hline & & & ARL & 2758.56 & 1372.1 & 251.24 & 157.23 & 136.49 & 127.48 \\
\hline
\end{tabular}


Tablo 4. Süreç kontrol altındayken medyan kontrol kartı için seçilen keyfi $m, n$ ve $P_{0}=0.9973$ değerlerine göre belirlenen $A K L=X_{a}$ değerleri için hesaplanan $F A R$ ve $A R L_{0}$ değerlerinin tablosu

\begin{tabular}{|c|c|c|c|c|c|c|c|c|c|}
\hline & & & \multicolumn{7}{|c|}{ Referans örneklem hacmi - $m$} \\
\hline$P_{0}$ & $n$ & $j$ & & 50 & 100 & 250 & 500 & 750 & 1000 \\
\hline \multirow{3}{*}{0.9973} & \multirow{3}{*}{5} & \multirow{3}{*}{3} & $(a)$ & (3) & (6) & (17) & (33) & (50) & (67) \\
\hline & & & $F A R$ & 0.0015 & 0.0018 & 0,0027 & 0,0026 & 0,0026 & 0,0027 \\
\hline & & & $A R L$ & $\infty$ & 1694.72 & 501.12 & 457.98 & 418.63 & 400.72 \\
\hline \multirow{3}{*}{0.9973} & \multirow{3}{*}{11} & \multirow{3}{*}{6} & (a) & (7) & (14) & (216) & $(429)$ & $(641)$ & (810) \\
\hline & & & FAR & 0.0025 & 0.0023 & 0.0027 & 0.0026 & 0.0027 & 0.0026 \\
\hline & & & $A R L$ & 34075.1 & 2206.82 & 879.6 & 583.6 & 488.9 & 465.7 \\
\hline \multirow{3}{*}{0.9973} & \multirow{3}{*}{15} & & (a) & (8) & (17) & (45) & (92) & (139) & (185) \\
\hline & & \multirow[t]{2}{*}{8} & FAR & 0.0019 & 0.0021 & 0.0024 & 0.0026 & 0,0027 & 0.0026 \\
\hline & & & $A R L$ & $\infty$ & 4315.23 & 827.2 & 528.49 & 460.26 & 446.48 \\
\hline \multirow{3}{*}{0.9973} & \multirow{3}{*}{21} & \multirow{3}{*}{11} & $(a)$ & (10) & (21) & (54) & $(111)$ & $(167)$ & (223) \\
\hline & & & FAR & 0.0026 & 0.0025 & 0.0024 & 0.0027 & 0.0027 & 0.0026 \\
\hline & & & $A R L$ & $\infty$ & 26386.9 & 1097.94 & 580.19 & 504.40 & 471.27 \\
\hline \multirow{3}{*}{0.9973} & \multirow{3}{*}{25} & \multirow{3}{*}{13} & (a) & (10) & (22) & (59) & (120) & (181) & (242) \\
\hline & & & FAR & 0.0016 & 0.002 & 0.0026 & 0.0026 & 0.0027 & 0.0027 \\
\hline & & & $A R L$ & $\infty$ & 26386.9 & 1194.88 & 640.84 & 531.02 & 484.97 \\
\hline \multirow{3}{*}{0.9973} & \multirow{3}{*}{31} & \multirow{3}{*}{16} & (a) & (11) & (25) & (64) & (131) & (197) & (263) \\
\hline & & & $F A R$ & 0.0018 & 0.002 & 0.0025 & 0.0027 & 0.0026 & 0.0027 \\
\hline & & & $A R L$ & 4519.68 & 4028.62 & 1670.01 & 712.81 & 589.34 & 514.55 \\
\hline
\end{tabular}

eşitsizliğinden bulunabilir [12],[3]. Süreç kontrol altında iken $Y_{j: n} \leq X_{b: m}$ olayının olasılı̆̆

$$
\begin{aligned}
& p_{U}=P\left(Y_{j: n} \leq X_{b: m}\right)=E_{X_{b: m}} P\left(Y_{j: n} \leq X_{b: m} \mid X_{b: m}\right) \\
& \quad=E_{X_{b: m}} P\left(G\left(Y_{j: n}\right) \leq G\left(X_{b: m}\right) \mid X_{b: m}\right) \\
& \quad=E_{U_{b: m}} P\left(U_{j: n} \geq G F^{-1}\left(U_{b: m}\right) \mid U_{b: m}\right) \\
& \quad=\int_{0}^{1} P\left(U_{j: n} \geq G F^{-1}(t) \mid U_{b: m}=t\right) f(t) d t \\
& =\int_{0}^{1}\left(\int_{0}^{G F^{-1}(t)} \frac{1}{B(j, n-j+1)} u^{j-1}(1-u)^{n-j} d u\right) f(t) d t
\end{aligned}
$$

$f(t), U_{b: m}$ sıra istatistiğinin olasılık yoğunluk fonksiyonu olmak üzere

$$
\begin{aligned}
p_{U}= & \int_{0}^{1}\left[\frac{1}{B(j, n-j+1)} \sum_{h=0}^{n-j} \frac{(-1)^{h}}{j+h}\left(\begin{array}{c}
n-j \\
h
\end{array}\right) \times\right. \\
& \left.\left(G F^{-1}(t)\right)^{(j+h)}\right] \frac{m ! t^{b-1}(1-t)^{m-b}}{(b-1) !(m-b) !} d t
\end{aligned}
$$

elde edilir. $H_{0}: F(x)=G(x)$ hipotezinin doğruluğu altında $G F^{-1}(t)=F F^{-1}(t)=t$ olacağından $p_{U}$ olasılığ

$$
\begin{aligned}
p_{U}= & \int_{0}^{1}\left[\frac{1}{B(j, n-j+1)} \sum_{h=0}^{n-j} \frac{(-1)^{h}}{j+h}\left(\begin{array}{c}
n-j \\
h
\end{array}\right) \times\right. \\
& \left.(t)^{(j+h)}\right] \frac{m !}{(a-1) !(m-a) !} t^{a-1}(1-t)^{m-a} d t
\end{aligned}
$$

olacaktır. Bu durumda yanlış alarm oranı

$$
\begin{aligned}
F A R= & 1-\int_{0}^{1}\left[\frac{1}{B(j, n-j+1)} \sum_{h=0}^{n-j} \frac{(-1)^{h}}{j+h}\right. \\
& \left.\times\left(\begin{array}{c}
n-j \\
h
\end{array}\right)(t)^{(j+h)}\right] \frac{m ! t^{b-1}(1-t)^{m-b}}{(b-1) !(m-b) !} d t
\end{aligned}
$$

şeklindedir.

Çalışma uzunluğu rastgele değişkeni $N$ 'in dağılımı, $p_{U}=P\left(Y_{j: n} \leq X_{b: m}\right)$ olasılığı ile geometrik dağılımına sahiptir. $N$ rastgele değişkeninin dağılımı

$$
\begin{aligned}
& P(N=k)=E_{X_{b: m}}\left(\left(p_{U}(x)\right)^{k-1}-\left(p_{U}(x)\right)^{k}\right), \\
& k=1,2,3, \ldots \\
& E_{X_{b: m}}\left(p_{U}(x)^{k}\right)=E_{U_{b: m}}\left[P\left(U_{(j: n)} \leq G F^{-1}\left(U_{(b: m)}\right)\right)\right]^{k} \\
& =\int_{0}^{1}\left[P\left(U_{(j: n)} \leq G F^{-1}(t)\right)\right]^{k} f(t) d t \\
& =\int_{0}^{1}\left[\int_{0}^{G F^{-1}(t)} \frac{1}{B(j, n-j+1)} u^{j-1}(1-u)^{n-j} d u\right]^{k} f(t) d t \\
& =\int_{0}^{1}\left[\int_{0}^{k} \frac{1}{B(j, n-j+1)} u^{j-1}(1-u)^{n-j} d u\right]^{k} \\
& \quad \times \frac{m !}{(b-1) !(m-b) !} t^{b-1}(1-t)^{m-b} d t
\end{aligned}
$$


$=\int_{0}^{1}\left[\frac{1}{B(j, n-j+1)} \sum_{h=0}^{n-j} \frac{(-1)^{h}}{j+h}\left(\begin{array}{c}n-j \\ h\end{array}\right)\right.$

$$
\left.\times\left(G F^{-1}(t)\right)^{(j+h)}\right]^{k} \frac{m ! t^{b-1}(1-t)^{m-b}}{(b-1) !(m-b) !} d t
$$$$
=D_{U}^{*}(k)
$$

$P(N=k)=D_{U}^{*}(k-1)-D_{U}^{*}(k)$,

$k=1,2,3, \ldots$ ve $D_{U}^{*}(0)=1$

dır. Süreç kontrol altındayken çalışma uzunluğunun dağılımı

$$
\begin{gathered}
P(N=k)=D_{U}(k-1)-D_{U}(k), \\
k=1,2,3, \ldots \text { ve } D_{U}(0)=1
\end{gathered}
$$

olmak üzere (17) eşitliğinde $F=G$ ve $G F^{-1}(t)=$ $F F^{-1}(t)=$ tolacağından

$$
\begin{aligned}
D_{U}(k) & =\int_{0}^{1}\left[\frac{1}{B(j, n-j+1)} \sum_{h=0}^{n-j} \frac{(-1)^{h}}{j+h}\left(\begin{array}{c}
n-j \\
h
\end{array}\right)(t)^{(j+h)}\right]^{k} \\
& \times \frac{m !}{(b-1) !(m-b) !} t^{b-1}(1-t)^{m-b} d t
\end{aligned}
$$

\begin{tabular}{|c|c|c|c|c|c|c|c|c|c|}
\hline & & & \multicolumn{7}{|c|}{ Referans örneklem hacmi m } \\
\hline$P_{0}$ & $n$ & $j$ & & 50 & 100 & 250 & 500 & 750 & 1000 \\
\hline \multirow{3}{*}{0.95} & \multirow{3}{*}{5} & \multirow{3}{*}{3} & $(b)$ & (43) & (84) & (206) & $(408)$ & (611) & (814) \\
\hline & & & $F A R$ & 0.0492 & 0.0465 & 0,0476 & 0,0497 & 0,0495 & 0,0494 \\
\hline & & & $A R L$ & 635.7 & 214.9 & 139.1 & 114.5 & 113.1 & 104.6 \\
\hline \multirow{3}{*}{0.95} & \multirow{3}{*}{11} & \multirow{3}{*}{6} & $(b)$ & $(40)$ & (76) & (186) & (368) & (550) & (732) \\
\hline & & & $F A R$ & 0.039 & 0.0477 & 0.0469 & 0.0487 & 0.0494 & 0.0497 \\
\hline & & & $A R L$ & 277.8 & 49.9 & 29.2 & 23.8 & 22.4 & 21.6 \\
\hline \multirow{3}{*}{0.95} & \multirow{3}{*}{15} & \multirow{3}{*}{8} & $(b)$ & (38) & (73) & (179) & $(354)$ & (529) & $(704)$ \\
\hline & & & $F A R$ & 0.0497 & 0.057 & 0.047 & 0.0484 & 0,0489 & 0.0492 \\
\hline & & & $A R L$ & $\infty$ & 60.1 & 32 & 25 & 23.2 & 22.3 \\
\hline \multirow{3}{*}{0.95} & \multirow{3}{*}{21} & \multirow{3}{*}{11} & (b) & (37) & (71) & (172) & $(340)$ & $(508)$ & $(676)$ \\
\hline & & & $F A R$ & 0.047 & 0.045 & 0.0473 & 0.0486 & 0.0493 & 0.0492 \\
\hline & & & $A R L$ & $\infty$ & 111.7 & 36.1 & 26.5 & 114 & 22.9 \\
\hline \multirow{3}{*}{0.95} & \multirow{3}{*}{25} & \multirow{3}{*}{13} & (b) & (37) & (70) & (169) & (333) & (498) & (663) \\
\hline & & & $F A R$ & 0.0378 & 0.0433 & 0.0465 & 0.0496 & 0.0493 & 0.0491 \\
\hline & & & $A R L$ & 1745.5 & 170.7 & 40.5 & 26.9 & 24.6 & 23.5 \\
\hline \multirow{3}{*}{0.95} & \multirow{3}{*}{31} & \multirow{3}{*}{16} & $(b)$ & (36) & (68) & (165) & (326) & (487) & (648) \\
\hline & & & $F A R$ & 0.044 & 0.0497 & 0.0481 & 0.0487 & 0.0489 & 0.0491 \\
\hline & & & $A R L$ & 4041.4 & 223.9 & 44.7 & 29.3 & 25.7 & 24.2 \\
\hline
\end{tabular}

Tablo 5. Süreç kontrol altındayken medyan kontrol kartı için seçilen keyfi $m, n$ ve $P_{0}=0.95$ değerlerine göre belirlenen

\begin{tabular}{|c|c|c|c|c|c|c|c|c|c|}
\hline \multirow[b]{2}{*}{$P_{0}$} & \multirow[b]{2}{*}{$n$} & & \multicolumn{7}{|c|}{ Referans örneklem hacmi m } \\
\hline & & $j$ & & 50 & 100 & 250 & 500 & 750 & 1000 \\
\hline \multirow{3}{*}{0.99} & \multirow{3}{*}{5} & \multirow{3}{*}{3} & (b) & (48) & (92) & $(227)$ & $(458)$ & $(674)$ & (898) \\
\hline & & & FAR & 0.0007 & 0.01 & 0,0092 & 0,0099 & 0,0098 & 0,0097 \\
\hline & & & ARL & 275351 & 317.5 & 165.7 & 122.7 & 116.2 & 113.1 \\
\hline \multirow{3}{*}{0.99} & \multirow{3}{*}{11} & \multirow{3}{*}{6} & (b) & (44) & (84) & (205) & (407) & $(608)$ & (810) \\
\hline & & & FAR & 0.0079 & 0.0097 & 0.0098 & 0.0097 & 0.0099 & 0.0098 \\
\hline & & & ARL & $\infty$ & 549.9 & 180.66 & 136.3 & 120.3 & 116.3 \\
\hline \multirow{3}{*}{0.99} & \multirow{3}{*}{15} & \multirow{3}{*}{8} & (b) & (42) & (81) & $\begin{array}{l}(197) \\
\end{array}$ & $(390)$ & $\begin{array}{l}(529) \\
\end{array}$ & (775) \\
\hline & & & FAR & 0.01 & 0.0093 & 0.0094 & 0.0096 & 0,0097 & 0.001 \\
\hline & & & ARL & $\infty$ & 224.8 & 217 & 145.8 & 23.2 & 118 \\
\hline \multirow{3}{*}{0.99} & \multirow{3}{*}{21} & \multirow{3}{*}{11} & (b) & (41) & (78) & $(188)$ & $(340)$ & $(556)$ & (740) \\
\hline & & & FAR & 0.0082 & 0.0088 & 0.01 & 0.0099 & 0.01 & 0.001 \\
\hline & & & ARL & $\infty$ & $\infty$ & 251 & 154.4 & 133.1 & 123.8 \\
\hline \multirow{3}{*}{0.99} & \multirow{3}{*}{25} & \multirow{3}{*}{13} & (b) & $(40)$ & (76) & (184) & $(364)$ & $(544)$ & (724) \\
\hline & & & FAR & 0.0097 & 0.01 & 0.0099 & 0.0098 & 0.0097 & 0.0097 \\
\hline & & & ARL & 458368 & 2999.9 & 294.8 & 169.3 & 143.1 & 132 \\
\hline \multirow{3}{*}{0.99} & \multirow{3}{*}{31} & \multirow{3}{*}{16} & (b) & (39) & (75) & $(180)$ & (354) & (529) & (704) \\
\hline & & & FAR & 0.01 & 0.008 & 0.0091 & 0.01 & 0.0098 & 0.0098 \\
\hline & & & ARL & 9477 & 5395.3 & 422 & 183.1 & 150.5 & 137 \\
\hline
\end{tabular}
$A K L=X_{b: m}$ değerleri için hesaplanan $F A R$ ve $A R L_{0}$ değerlerinin tablosu

Tablo 6. Süreç kontrol altındayken medyan kontrol kartı için seçilen keyfi $m, n$ ve $P_{0}=0.99$ değerlerine göre belirlenen $A K L=X_{b: m}$ değerleri için hesaplanan $F A R$ ve $A R L_{0}$ değerlerinin tablosu 
Tablo 7. -Süreç kontrol altındayken medyan kontrol kartı için seçilen keyfi $m, n$ ve $P_{0}=0.9973$ değerlerine göre belirlenen $A K L=X_{b: m}$ değerleri için hesaplanan $F A R$ ve $A R L_{0}$ değerlerinin tablosu

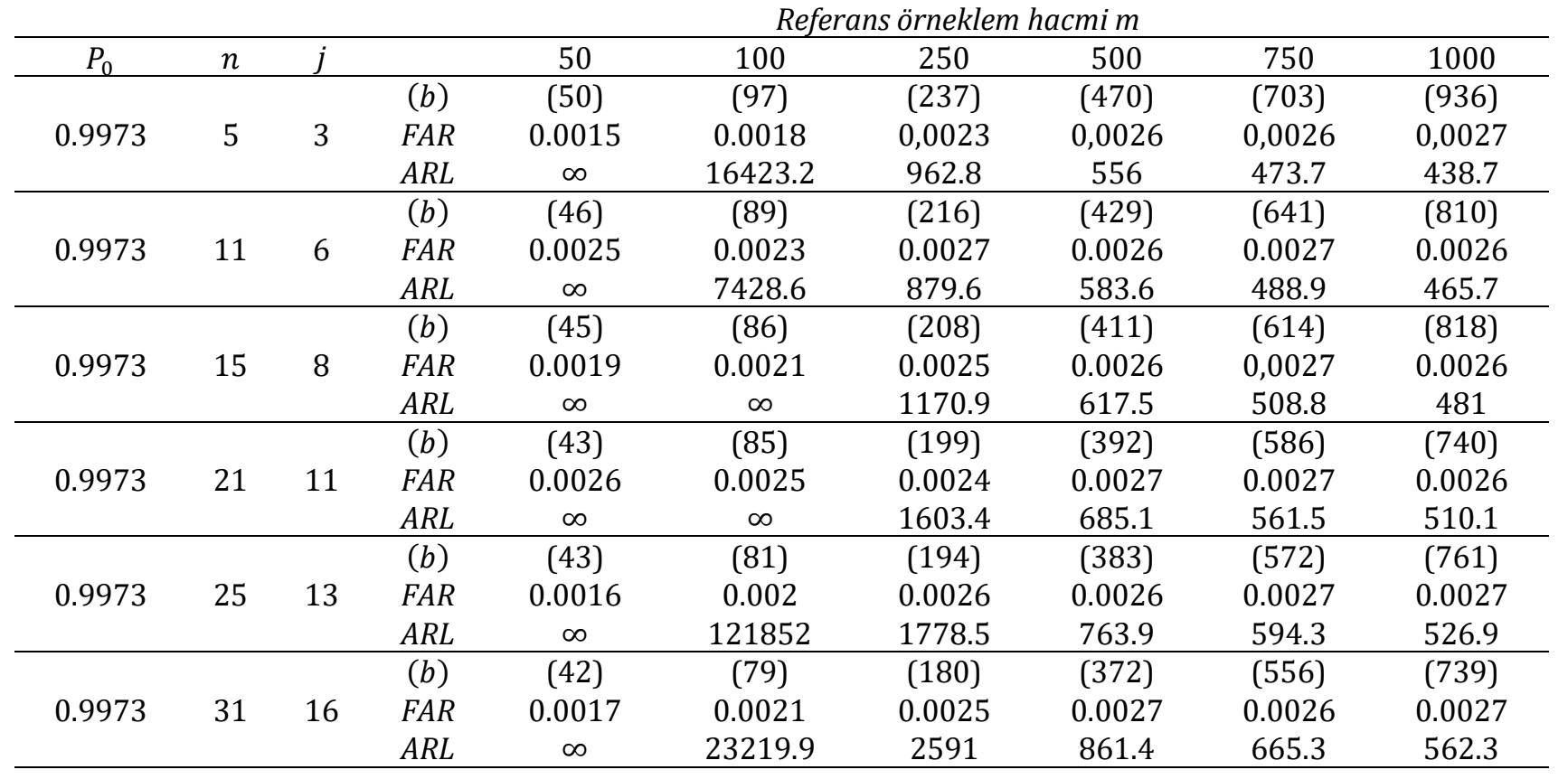

elde edilir. Ortalama çalışma uzunluğu ise

$$
A R L=\sum_{k=0}^{\infty} E_{X_{b: m}}\left(p_{U}(x)^{k}\right)=\sum_{k=0}^{\infty} D_{U}^{*}(k)
$$

dır. (17) eşitliği kullanılarak

$$
\begin{aligned}
A R L= & \sum_{k=0}^{\infty} \int_{0}^{1}\left[\frac{1}{B(j, n-j+1)} \sum_{h=0}^{n-j} \frac{(-1)^{h}}{j+h}\left(\begin{array}{c}
n-j \\
h
\end{array}\right)\right. \\
& \left.\left(G F^{-1}(t)\right)^{(j+h)}\right]^{k} \times \frac{m ! t^{b-1}(1-t)^{m-b}}{(b-1) !(m-b) !} d t
\end{aligned}
$$

$C_{U}(t, j, n, F, G)$

$=\frac{1}{B(j, n-j+1)} \sum_{h=0}^{n-j} \frac{(-1)^{h}}{j+h}\left(\begin{array}{c}n-j \\ h\end{array}\right)\left(G F^{-1}(t)\right)^{(j+h)}$

olmak üzere

$$
\begin{aligned}
A R L= & \int_{0}^{1} \sum_{k=0}^{\infty}\left(C_{U}(t, j, n, F, G)\right)^{k} \frac{m ! t^{b-1}(1-t)^{m-b}}{(b-1) !(m-b) !} d t \\
A R L= & \int_{0}^{1}\left[1-C_{U}(t, j, n, F, G)\right]^{-1} \\
& \times \frac{m !}{(b-1) !(m-b) !} t^{b-1}(1-t)^{m-b} d t
\end{aligned}
$$

dır. Süreç kontrol altındayken yani $H_{0}: F=G$ olması durumunda (21) eșitliğinden

$$
\begin{aligned}
A R L_{0}= & \sum_{k=0}^{\infty} D(k)=\int_{0}^{1}\left[1-C_{U}(t, j, n)\right]^{-1} \\
& \times \frac{m !}{(b-1) !(m-b) !} t^{b-1}(1-t)^{m-b} d t
\end{aligned}
$$

biçiminde elde edilir. Burada

$C(t, j, n)=\frac{1}{B(j, n-j+1)} \sum_{h=0}^{n-j} \frac{(-1)^{h}}{j+h}\left(\begin{array}{c}n-j \\ h\end{array}\right)(t)^{(j+h),} \operatorname{dir}$.

Așağıdaki tablolar ön istatistiğine dayalı olarak oluşturulan medyan kontrol kartları için sırasıyla $m=50,100,250,500,750,1000 ; n=5,11,15,25,31$; $P_{0}=0.95,0.99,0.9973$ için $b(13$ formülünden), yanlış alarm oranı (FAR) (16 formülünden) ve ortalama Çalışma uzunluğu $A R L_{0}$ (23 formülünden) değerleri hesaplanmıştır.

Ön istatistiği kullanılarak oluşturulan kontrol kartları tablolarına bakıldığında referans örneklem boyutunun büyük değerleri için $A R L_{0}$ değerleri oldukça iyi sonuç vermiştir. Ancak özellikle $m$ 'nin 100 'den küçük olması durumunda $A R L_{0}$ değerleri iyi sonuç vermemiş̧ir. $\mathrm{Bu}$ problemi ortadan kaldırmak için $b^{\prime}$ nin seçiminde önceden seçilen $A R L_{0}=$ 500 değeri kullanılarak farklı referans örneklem boyutları için regresyon denklemi oluşturulabilir [7]. $n=5, j=3$ için farklı $m$ değerleri için $b^{\prime}$ nin seçiminde kullanılacak regresyon denklemi olarak

$$
\hat{b}=-1.1468+0.940206 m
$$


denkleminin kullanılması önerilir. Tablo 8'de ise seçilen bazı çarpık, hafif ya da ağır kuyruklu dağılımlar için süreç kontrol altında iken medyan kontrol kartları ve Shewhart kontrol kartları için $A R L_{0}$ değerleri hesaplanmıştır.

Tablo 8. Bazı dağılımlar için $A R L_{0}$ değerleri

\begin{tabular}{ccc} 
Dağılımlar & $\begin{array}{c}\text { Medyan } \\
\text { kontrol karı }\end{array}$ & $\begin{array}{c}\text { Shewhart } \\
\text { kontrol } \\
\text { kartı } * *\end{array}$ \\
\hline Normal $(0,1)$ & 505.52 & 500 \\
Laplace $(0,1 / \sqrt{2})$ & 505.52 & 251.04 \\
Gamma $(1,1)$ & 505.52 & 89.29 \\
Gamma $(4,1 / 2)$ & 505.52 & 158.79 \\
Cauchy $(\lambda=0.2605)$ & 505.52 & 16.38 \\
Uniform $(0, \sqrt{3})$ & 505.52 & 2112.01 \\
\hline${ }^{*}=1000, n=5, j=3, b=939 P_{0}=0.998,{ }^{* *} n=5$,
\end{tabular}

Tablodan da görüldüğü gibi bazı çarpık ve hafif ya da ağır kuyruklu dağılımlar için $A R L_{0}$ değerleri hesaplanmıștır. Dağılımdan bağımsız olan ön istatistiği kullanılarak oluşturulan kontrol kartlarından elde edilen $A R L_{0}$ değerleri değişmemiştir. Fakat Shewhart ortalama kontrol kartları bu tür dağılımlardan olumsuz etkilenmekte elde edilen $A R L_{0}$ değerleri iyi sonuç vermemektedir.

\section{Uygulama}

$\mathrm{Bu}$ kesimde yukarıda verilen tabloların nasıl kullanılacağını açıklamak için bir veri seti üzerinde uygulama yapılmıştır. Keyfi $m, n$ ve $P_{0}$ değerlerinin kombinasyonlarına göre bulunan $a, b$ değerlerini Tablo 5'den okuyarak medyan kontrol kartının çizimine örnek vermek için bir veri seti üzerinde uygulama yapılmıştır. Bunun için Dou and Ping den alınan akışkanlık verisi kullanılmıștır [16]. Bazı kimyasalların üreticisi, belirli bir kimyasal maddenin akışkanlıklarını üretim hattından izlemek istemektedir. Süreçte akışkanlığın artmasına neden olan bozuklukları tespit etmenin önemli olduğunu varsayalım. Akışkanlık ne kadar yüksekse sıvı o kadar yavaş akar. Suyun akışkanlığı 0.894, zeytinyağının ki 81, balın ki 2000-10000 arasıdır. Veri setini elde edebilmek için akışkanlığın rastgele ölçümleri, alt gruplar elde edilinceye kadar arka arkaya seçilir (ardışık gözlemler, Dou and Ping) den her satır boyunca okunarak elde edilir [16].

$\mathrm{Bu}$ veri seti için Minitab 17'de yapılan analizler sonucunda $\bar{x}=3.17933$, st. sapma $=2.47510$, medyan=2,6752, $\min =0,0205$, $\operatorname{maks}=11,6354$, çarpıklı katsayısı=1,23809, basıklık katsayısı=1,48083 olarak bulunmuştur. Anderson Darling uyum iyiliği sonuçlarına göre veri setinin Normal dağılıma uymadığı görülmiştir $(A D=6.241$, pdeğeri <0,005). Dolayısıyla bu verilere klasik Shewhart kontrol kartlarını çizmek uygun değildir, çünkü I. tip hata yapma olasılığı ideal değerden farklı olacaktır.

Referans örnekleminden $\quad \overline{\bar{x}}=\frac{\sum_{i=1}^{250} \bar{x}_{i}}{250}=3.1793344$, $\bar{R}=5.47123$ ve $\hat{\sigma}=\frac{\bar{R}}{d_{2}}=\frac{5.47123}{2.326}=2.3522$ olarak hesaplanmıştır ve Tek yanlı Shewhart kontrol grafiğinin üst limiti $\ddot{\mathrm{U}} K L=\overline{\bar{\chi}}+1.645 \frac{\widehat{\sigma}}{\sqrt{n}}=4.90977$ olarak elde edilir. $d_{2}$ değeri, Montgomery'den okunan bir kontrol limiti katsayısıdır [2].

$m=50 \times 5=250, n=5, j=3$ için simetrik parametrik olmayan kontrol kartları için $P_{0}=0.95$ için Tablo 5'den $b=206$ olarak okunur. Buna göre referans örneklemdem Ü $K L=X_{206: 250}=5.319$ ve olarak bulunur.

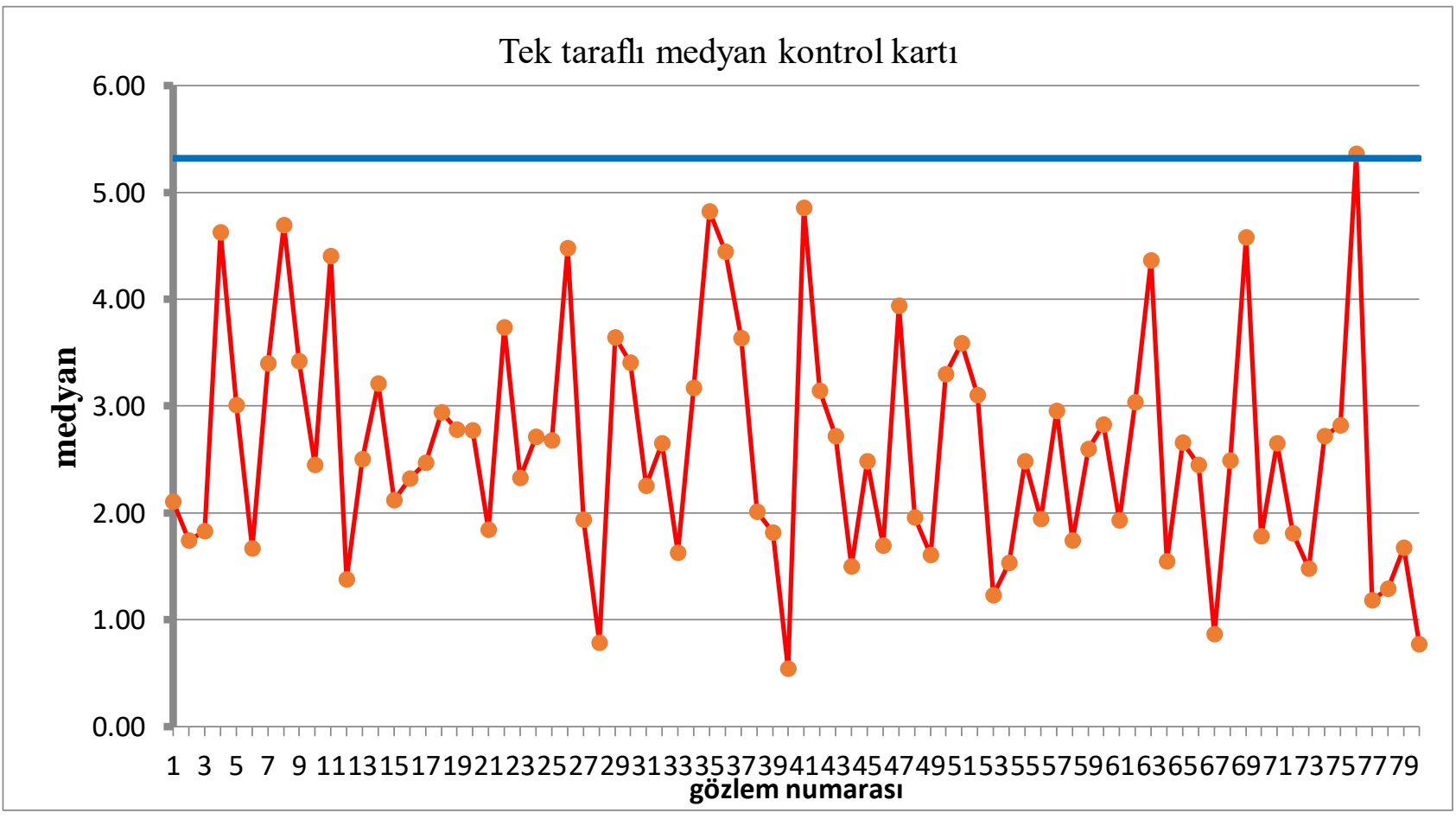

Şekil 4. Akışkanlık verisi için tek taraflı medyan kontrol kartı 


\section{Tek taraflı Shewhart Kontrol çizelgesiı}

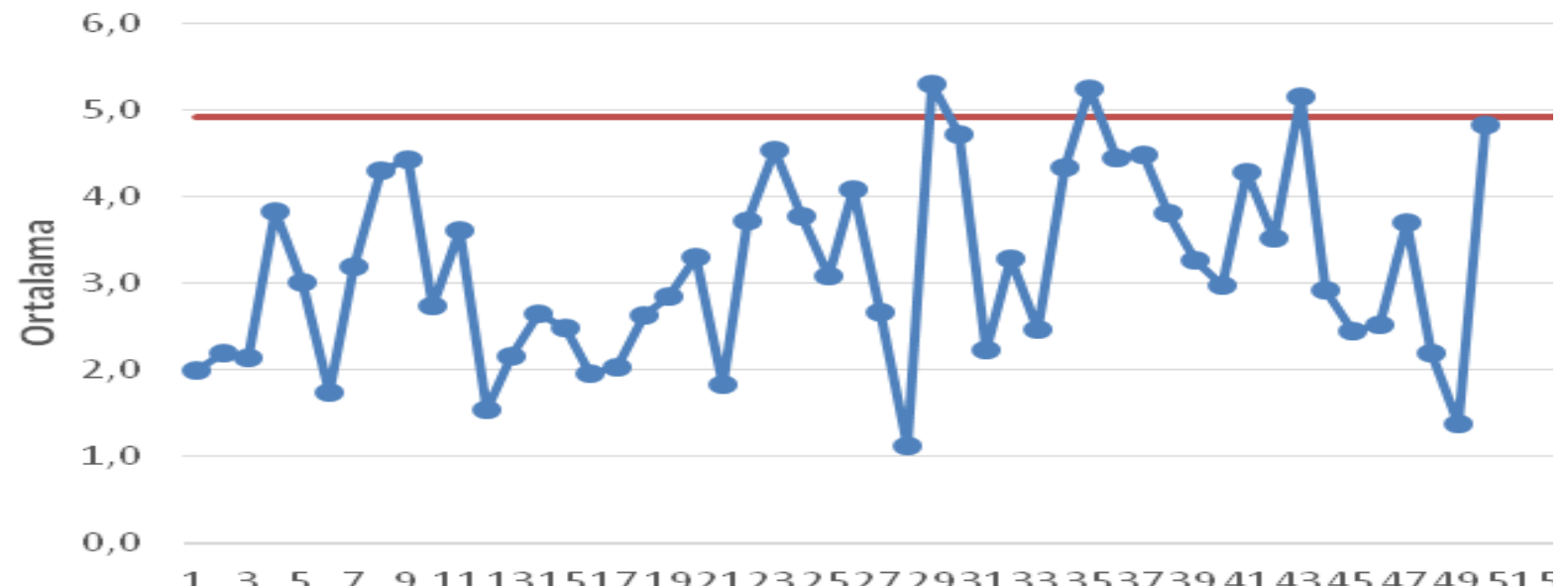

gözlem numarası

Şekil 5. Akışkanlık verisi için tek taraflı Shewhart kontrol kartı

Yukarıda verilen veri seti kullanılarak medyan kontrol kartı ve Shewhart kontrol kartı çizilerek sırasıyla Şekil-4 ve Şekil-5'de verilmiştir. Faz I de 50 örneklem kullanılmıștır. Faz II'de 30 örneklem kullanılmıștır. Medyan kontrol kartı için Ü $K L=$ $X_{206: 250}=5.319$ olarak Shewhart kontrol kartı için $\ddot{U} K L=4.90977$ olarak hesaplanmıştır. Buna göre Shewhart kontrol kartı için bulunan kontrol limitlerinin daha dar olduğu görülmektedir. Shewhart kontrol kartı çiziminde kitle standart sapmasının tahmin edicisi olarak örneklem genişliğinden yararlanılmıştır. Tek yanlı medyan kontrol kartı için Tablo 5'den $\alpha=0.05$ için $F A R=0.0476$ ve $A R L=$ 139.1 olduğu okunur.

Şekil 4'de görülen medyan kontrol kartında Faz I'de süreç kontrol altındadır. Bulunan kontrol limitleri kullanılarak Faz II aşamasına geçilmiştir. Faz II'de yer alan 77. sıradaki medyan değerinin üst kontrol limiti dışına çıktığı gözlenmiştir. Bu durum süreçte bir kaymanın olduğuna işaret etmektedir. Veri setinde 77. sırada bulunan örneklemin elde edilme süreci tekrardan değerlendirilerek sürecin iyileștirilmesi için gerekli çalışmaların yapılması ilgili işletmeye önerilir.

Şekil 5'de ise klasik Shewhart ortalama kontrol kartı yer almaktadır. Grafikte Faz I aşamasında süreç kontrol dışına çıkmış olarak görülmektedir. Bu nedenle Faz II'ye geçilmemiştir. Normal dağılıma sahip olmayan akışkanlık verisi için Shewhart kontrol kartının yanıltıcı olduğu görülmektedir.

\section{Sonuç ve Öneriler}

Bir üretim sürecinde normal dağılım varsayımının şüpheli olduğu durumda ve çarpık ya da ağır kuyruklu dağllım söz konusu olduğunda tek taraflı Shewhart kontrol kartı yerine ön istatistiklere dayalı ve dağılımdan bağımsız olan tek taraflı medyan kontrol kartlarının kullanılması önerilir. Bir imalat hattında sürecin istatistiksel kotrolü için yapılan denetlemeler ile verimliliği artırmak, yüksek kar elde etmek ve zaman tasarrufu elde etmek açısından doğru kontrol kartının seçilmesi çok önemlidir. Bu çalışmada dağılımdan bağımsız tek taraflı kontrol kartlarının kullanımı için farklı $P_{0}, m, n$ değerleri için sıra istatistiklerine dayalı kontrol limitlerinin $A R L$ ve $F A R$ değerleri hesaplanmış ve orijinal tablolar olarak verilmiştir. Ayrıca bazı çarpık ve ağır kuyruklu dağılımlar için $A R L_{0}$ değerleri hesaplanmıştır. Ülkemizde üretim yapan ve istatistiksel kalite kontrol sürecine önem veren sanayi kuruluşları için hazırlanan bu tablolar büyük kullanım kolaylığı sağlayacaktır.

\section{Kaynakça}

[1] Shewhart, W. A. 1926. Quality Control Charts. Bell System Technical Journal, 5(4), 593-603.

[2] Montgomery, D. C. 1991. Introduction to Statistical Quality Control. 2th Edition, John Wiley, New York, 674s.

[3] Chakraborti, S., Graham, M. A. 2019. Nonparametric Statistical Process Control. 1st edition. John Wiley\&Sons Ltd, 424s.

[4] Bakir, S. T. Reynolds, M. R. Jr. 1979. A Nonparametric Procedure For Process Control Based on Within-Group Ranking. Technometrics, 21(2), 175- 183.

[5] Amin, R. W., Reynolds, M. R. Jr., Bakir, S. T. 1995. Nonparametric Quality Control Charts Based on The Sign Statistic. Communications in StatisticsTheory and Methods, 24(6), 1579-1623.

[6] Bakir, S. T. 2006. Distribution-Free Quality Control Charts Based on Signed- Rank-Like 
Statistics. Communications in Statistics- Theory and Methods, 35(4), 743-757.

[7] Janacek, G. J. Meikle, S. E. 1997. Control Charts Based on Medians. The Statistician, 46(1), 1931.

[8] Balakrishnan, N., Triantafyllou, I. S., Koutras, M. V. 2009. Nonparametric Control Charts Based on Runs and Wilcoxon-Type Rank-Sum Statistics. Journal of Statistical Planning and Inference, 139(9), 3177-3192.

[9] Balakrishnan, N. Triantafyllou, I. S., Koutras, M. V. 2010. A Distribution-Free Control Chart Based on Order Statistics. Communications in Statistics-Theory and Methods, 39(20), 36523677.

[10] Chakraborti, V. L., Bakir, S T. 2001. Nonparametric Control Charts: An Overview And Some Results, Journal of Quality Technology, 33(3), 304- 315.

[11] Chakraborti, S., Van der Laan, P., Van de Wiel, M. A. 2004. A Class of Distribution-Free Control Charts. Journal of The Royal Statistical Society: Series C (Applied Statistics), 53(3), 443-462.
[12] Triantafyllou, I. S. 2018a. Nonparametric Control Charts Based on Order Statistics: Some Advances. Communications In StatisticsSimulation and Computation, 47(9), 2684-2702.

[13] Triantafyllou, I. S. 2018b. A New DistributionFree Control Scheme Based on Order Statistics. Journal of Nonparametric Statistics, 130.

[14] Shongwe , S. C., Malela-Majika, J. C. Rapoo E. M. 2019. One-Sided And Two-Sided W-Of-W RunsRules Schemes: an Overall Performance Perspective and the Unified Run-Length Derivations. Journal of Probability and Statistics, 6187060.

[15] Turhan, N. Yurt Oncel S. 2019. Süreç Ortalamasının İzlenmesi için Sıra İstatistiklerine Dayalı Kalite Kontrol Kartları. İstatistikçiler Dergisi:İstatistik ve Aktüerya, 12(2), 72-89.

[16] Dou, Y., Ping S. 2002. One-Sided Control Charts for the Mean of Positively Skewed Distributions. Total Quality Manage, 13(7), 1021-1033. 